\title{
Adrenoleukodystrophy Mimicking Multiple Sclerosis
}

\author{
J.M. Dooley and B.A. Wright
}

\begin{abstract}
We report a 47 year old woman who was initially diagnosed as having multiple sclerosis. She has subsequently been found to be heterozygous for adrenoleukodystrophy (ALD). The female carrier state for ALD may be associated with intermittent symptoms and it is therefore important to consider ALD in patients diagnosed as multiple sclerosis.
\end{abstract}

RÉSUMÉ: Une adrenoleucodystrophie imitant une sclérose en plaques Nous rapportons l'histoire d'une femme de 47 ans dont le diagnostic initial fut de sclérose en plaques. Plus tard il fut démontré qu'elle était hétérozygote pour l'adrénoleucodystrophie (ALD). L'état de porteur chez la femme peut être associé à des épisodes intermittents ce qui devrait nous inciter à considérer ce diagnostic différentiel dans ces cas précis.

Can. J. Neurol. Sci. 1985; 12: 73-74

The diagnosis of multiple sclerosis (MS) is based on clinical criteria, with supporting evidence from physiological and laboratory studies (McDonald and Halliday, 1977). More recently Poser et al. (1983) have provided new diagnostic criteria for the diagnosis of MS in patients participating in therapeutic trials. The non-specific nature of these criteria emphasizes the importance for the practising neurologist to consider conditions which may mimic MS clinically and in the laboratory. We report a patient in whom MS was initially diagnosed but who was later found to be heterozygous for adrenoleukodystrophy (ALD).

\section{CASE REPORT}

This patient, a 47 year old female, was first referred for evaluation of intermittent paresthesia of the left arm and leg in May 1980. The episodes lasted up to 48 hours and were associated with minimal weakness of the left leg. Her past history was unremarkable apart from urinary urgency and incontinence on 2 occasions. From 1980 to 1984 she continued to have periods of anesthesia and paresthesia in both feet which persisted for a few days before resolving spontaneously.

On examination she had mildly decreased hearing bilaterally. In the lower extremities proprioception and vibration perception were depressed in association with hyperreflexia of the deep tendon reflexes and extensor plantar responses. The remainder of the neurological examination was normal.

Investigations included high voltage elect rophoresis of the CSF which revealed an oligoclonal pattern. Brainstem auditory evoked responses (BAER) demonstrated a prolonged wave I-V latency. Both a cranial CT Scan and a myelogram were normal. A diagnosis of MS was made on the basis of the clinical and laboratory findings.
The patient was not seen again until 1983, when her 11 year old son presented with a rapidly progressive CNS illness, which was diagnosed as adrenoleukodystrophy.

Further evaluation of the family revealed that the patient's sister had an episode of lower extremity numbness in 1978 and on examination had hyperreflexia at the knees and extensor plantar responses. Both her maternal grandfather and 2 greatuncles had been confined to wheelchairs because of progressive spinal cord dysfunction (Fig. 1)

Plasma and fibroblast levels of very long chain fatty acids (VLCFA) were measured by Dr. H.W. Moser. The C26:0/C22:0 ratio in the patient's cultured skin fibroblasts was 0.336 , which is consistent with the heterozygous state for ALD. The ratio in her clinically abnormal son was 0.641 , which is diagnostic of ALD.

\section{Discussion}

Adrenoleukodystrophy (ALD) is an $\mathrm{x}$-linked disorder of very long chain fatty acid metabolism which is manifested by central and peripheral nervous system demyelination and adrenal atrophy. Several phenotypes have been described ( $O$ 'Neill and Moser, 1982): 1) a progressive CNS demyelination with some degree of adrenal dysfunction in young boys, 2 ) a myelopathy in female carriers, 3) a progressive myelopathy in adult males, 4) cerebral and spinal dysfunction in adolescent males, 5) x-linked Addison's Disease without neurological impairment, and 6) a connatal form with possible autosomal recessive inheritance.

The demyelination in ALD heterozygous females has been shown to extend above the spinal cord. Moloney and Masterson (1982) demonstrated a prolongation of the BAER I-V interwave latency in 3 obligate ALD heterzygotes, indicating brain stem involvement. 


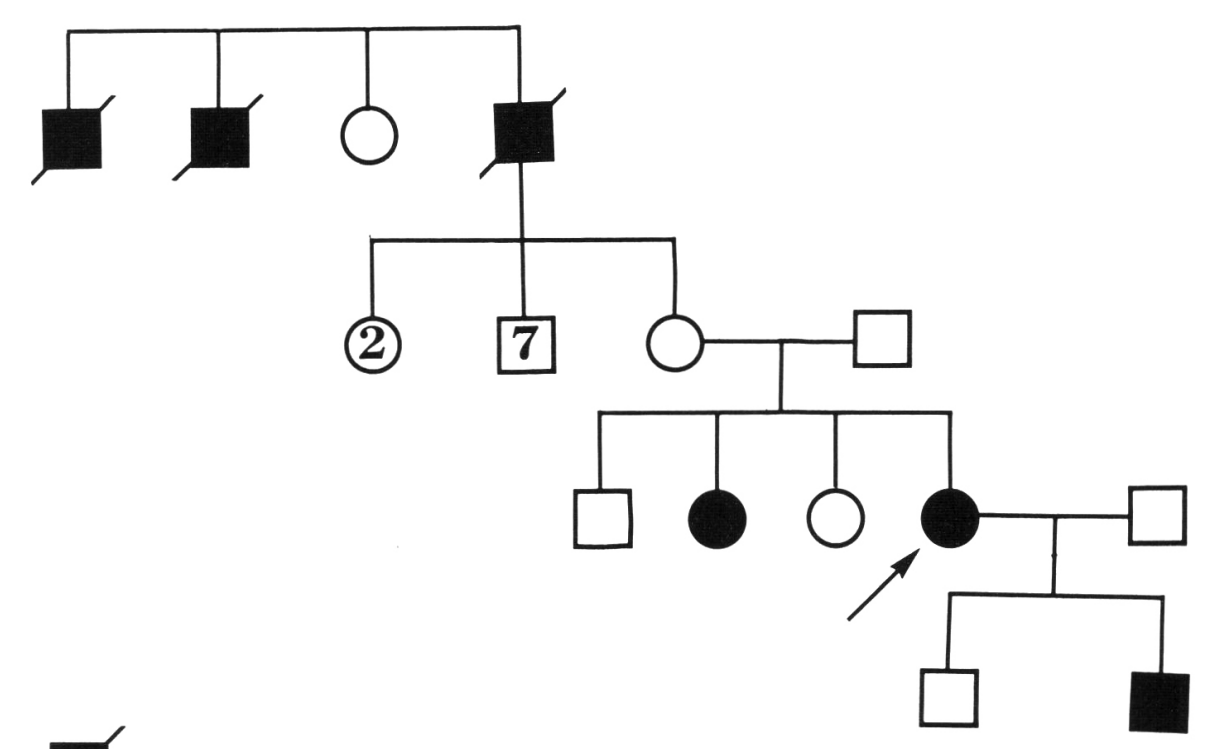

Figure I - FamilyPedigree;progressive myelo pathy in adult males; sympotamatic carrier females; progressive CNS degeneration in adolescent male.

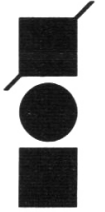

PROGRESSIVE MYELOPATHY IN ADULT MALES

SYMPTOMATIC CARRIER FEMALES

PROGRESSIVE CNS DEGENERATION IN ADOLESCENT MALE

The clinical features of our patient in association with CSF oligoclonal banding and evidence of brain stem dysfunction on BAER are suggestive of MS. Her ALD heterozygous state is confirmed by the skin fibroblast $\mathrm{C} 26: 0 / \mathrm{C} 22: 0$ ratio in association with the BAER findings (Moloney and Masterson, 1982) and the family history of neurological and adrenal dysfunction which is consistent with an X-linked pattern of inheritance (Fig. 1).

The intermittent nature of our patient's course led to an initial diagnosis of MS, despite previous reports of relapsing and remitting symptoms in ALD (Walsh, 1980). It is impossible, however, to ascertain whether this patient has MS in addition to ALD, as the diagnostic tools for MS are non-specific. The confusion regarding the correct diagnosis stresses the importance of considering ALD in all suspected MS patients with a family history of either neurological disease or Addison's Disease (O'Neill et al., 1982). Plasma and fibroblast VLCFA levels should be performed in all such patients.

ALD is an $x$-linked condition with an inexorable clinical course. With prenatal diagnosis now possible (Moser et al., 1982 ) it is essential to recognize the carrier state.

\section{REFERENCES}

McDonald W, Halliday AM (1977) Diagnosis and classification of multiple sclerosis. British Med. Bull. 33: 4-8.

Moloney JBM, Masterson JG (1982) Detection of adrenoleukodystrophy carriers by means of evoked potentials. Lancet II: 852-853.

Moser HW, Moser AB, Powers JM et al. (1982) The prenatal diagnosis of adrenoleukodystrophy. Demonstrations of increased hexacosamoic acid levels in cultured amniocytes and fetal adrenal gland. Pediatr. Res. 16: 172-175.

O'Neill BP, Moser HW (1982) Adrenoleukodystrophy. Can. J. Neurol. Sci. 9: 449-452.

O'Neill BP. Moser HW, Saxena KM (1982) Familial x-linked Addison disease as an expression of adrenoleukodystrophy (ALD): Elevated C26 fatty acid in cultured skin fibroblasts. Neurol. 32: 543-547.

Poser CM, Paty DW, Scheinberg L et al. (1983) New diagnostic criteria for multiple sclerosis: guidelines for research protocols. Ann Neurol. 13: $227-231$

Walsh PJ (1980) Adrenoleukodystrophy. Report of two cases with relapsing and remitting courses. Arch. Neurol. 37: 448-450. 